\title{
Investigating the Determinants of Maternal Care Services Utilization in the Brong Ahafo Region of Ghana
}

\author{
Abdul-Karim Iddrisu', Dominic Otoo', Bashiru Mahama² \\ ${ }^{1}$ Department of Mathematics and Statistics, University of Energy and Natural Resources, Sunyani, Ghana \\ ${ }^{2}$ Environmental Health and Sanitation, College of Nursing and Midwifery, Nalerigu, Ghana \\ Email: karim@aims.ac.za
}

How to cite this paper: Iddrisu, A.-K., Otoo, D. andMahama, B. (2019) Investigating the Determinants of Maternal Care Services Utilization in the Brong Ahafo Region of Ghana. Open Journal of Statistics, 9, 309-326.

https://doi.org/10.4236/ojs.2019.93022

Received: February 8, 2019

Accepted: June 15, 2019

Published: June 18, 2019

Copyright $\odot 2019$ by author(s) and Scientific Research Publishing Inc. This work is licensed under the Creative Commons Attribution International License (CC BY 4.0).

http://creativecommons.org/licenses/by/4.0/

\begin{abstract}
Ghanaian governments have made some social interventions in order to reduce risks associated with pregnancy and child delivery. However, most pregnant women do not seek maternal care. Previous studies have examined factors contributing to maternal care services utilization in Ghana using national data which limit such study applicability in some areas with specific background characteristics. These studies have mostly limited it to rural areas where the utilization is very low. This study seeks to bridge the gaps identified by exploring the factors which influence maternal care utilization in urban and rural communities in the Brong Ahafo Region of Ghana. The Chi-Square test of association and the logistic regression models are used to analyze data obtained from the 2014 Ghana Demographic and Health Survey (DHS). The data analyses were carried out using R and STATA softwares. The results revealed that women with at least 5 children were less likely ( $\mathrm{OR}=0.374,95 \%$ CI: 0.173 - 0.796) to utilize antenatal care compared to those who had less than five live births. Educated women are three times likely (95\% CI: 1.929 5.257) to deliver at a health facility compared to uneducated women. Women from the rich wealth quintile were nearly 16.9 times more likely (95\% CI: 4.816 - 107.124) to deliver in a health facility compared to those from the poor wealth quintile. On the other hand, residing in rural communities makes it less likely ( $\mathrm{OR}=0.569,95 \% \mathrm{CI}: 0.350-0.913)$ for women to receive postnatal care within 2 months of delivery compared to living in urban communities. This study has demonstrated that maternal educational level plays a crucial role in maternal health care service utilization in the region. Therefore, government policies and programs aimed at providing more educational opportunities for girls in the region should be reinforced.
\end{abstract}




\section{Keywords}

Antenatal Care, Chi-Square, Institutional Delivery, Logistic Regression, Postnatal Care, Maternal Health

\section{Introduction}

Women are exposed to several risk factors during pregnancy and childbirth. Such risk factors could be death of a pregnant woman, transmission of infections from mother to child during pregnancy, premature delivery (which could lead to death of a child or delivery of a deformed child), malnutrition due to lack of understanding of necessary requirements for a healthy child. The well-being of the mother and child is also at risk if nursing mothers do not take into account the health implications of their diet. Reduction of these risk factors among women requires timely and adequate medical intervention. Global statistics show that more than 135 million women give birth per year and out of this number, approximately 20 million experience pregnancy-related complications during the postnatal period. Such complications could be fever, anemia, fistula, incontinence, infertility and depression [1]. Approximately 303,000 women died in 2015 as a result of such complications during pregnancy and childbirth [1]. This number of deaths in 2015 gives an indication that every day, approximately 830 women's deaths are associated with complications during pregnancy and childbirth [1].

Globally, it has been estimated that more than half a million women died during child delivery every year. Out of these deaths, about $99 \%$ are from developing countries. A large number of these deaths 47\% (251,000) and 48\% $(253,000)$ are from Africa and Asia respectively. About $4 \%(22,000)$ and less than $1 \%$ (2500) of these deaths occur in Latin America and the Caribbean [2].

The second leading cause of death (after HIV/AIDS) among women in their reproductive period, in developing countries, is complications associated with pregnancy and childbirth. It is known that [1] most of these deaths can be prevented by using skilled health assistant during childbirth and increase access to emergency obstetric care. However, most women rarely seek medical advice from skilled health professionals during antenatal and postnatal periods. Approximately $50 \%$ of the women receive the recommended minimum of at least 4 visits during the pregnancy. Women who rarely visit a health facility to seek medical advice are unlikely to detect symptoms (that may lead to complications) for appropriate health care and treatment at their (complications) early stages.

It has been estimated that, out of the total number of deaths from developing countries, more than $50 \%$ of the deaths are from Sub-Saharan Africa. Deaths associated with pregnancy and childbirth is extremely high among women from Sub-Saharan Africa with 1 death for every 26 mothers [1]. In developed countries, there is 1 maternal death for every 7300 mothers. This gives an indication 
that the frequency of deaths associated with pregnancy and childbirth in developing countries is approximately 281 times more than the maternal death in developed countries. Maternal mortality ratio associated with developing countries is 239 per 100,000 births and 12 per 100,000 births in the developed countries. There is a higher maternal mortality among women in rural, poorer and less educated communities in Sub-Saharan Africa.

Antenatal care (ANC), institutional delivery and postnatal care services utilization provides pregnant women with information, treat existing social and medical conditions, and screen for risk factors. However, utilization of these services in most developing countries is constrained due to various cultural, socio-economic, and demographic factors [3]. Globally, while 85 percent of pregnant women access antenatal care with skilled health personnel at least once, only six in ten (58 percent) receive at least four antenatal visits. In regions with the highest rates of maternal mortality, such as sub-Saharan Africa and South Asia, even fewer women received at least four antenatal visits (49\% and $42 \%$, respectively) [4].

The 2014 national statistics [5] showed that antenatal care by a health professional was $97.0 \%$, births at a health facility was $73.0 \%$ and the proportion of the births attended by a skilled health professional was estimated to be $74.0 \%$. It was estimated that $78 \%$ of women utilized postnatal services in the first two days of their postnatal period.

High maternal mortality continues to be a public health problem in Ghana and maternal mortality is 319/100,000 live births [6]. As a result, Ghana governments have made efforts to reduce maternal morbidities and mortalities. Among the efforts is the Ghana government's aim of reducing maternal mortality through free maternal health services policy to achieve the Millennium Development Goal 5 of 54 per 100,000 live births by 2015. However, this goal is yet to be achieved. Dating back from 2003, the governments of Ghana have advocated for increasing access to maternal health services as well as prenatal care through the free maternal health policy and the establishment of Community Based Health Planning and Services (CHPS) compounds. The purpose of these interventions was to lessen or removed the financial and health facility barriers to delivery and emergency care and also to improve access to and use of maternal and newborn health-care services [7].

However, despite these efforts by the Ghana governments, antenatal care, institutional delivery and postnatal care services utilization still continue to be a public problem in Ghana. According to the 2008 Ghana Demographic and Health Survey [8], although majority of Ghanaian women attended ANC visit (96.5\%) many (42.7\%) did so late (after the first trimester), while $36.5 \%$ had delivery without the assistance of a trained personnel (30.6\%) or anyone (5.9\%) [8]. According to the World Health Organization, in 2015, an estimated 2800 women in Ghana died during childbirth. This is not even the complete picture because deaths that take place outside of health facilities, especially in rural areas, where they are sometimes not recorded. 
In general, there are variations in the utilization of antenatal care, institutional delivery and postnatal care services. The factors affecting antenatal care, institutional delivery and postnatal care services varied by region, geographic area, and socio-economic and cultural settings [5] which calls for investigation of the area of socio-economic and culture-specific determinants of antenatal care, institutional delivery and postnatal care services.

\section{Methods}

In this section, we will introduce the study setting, describe the study sample and data source, and statistical methods used for the analysis.

\subsection{Study Setting}

This study took place at Brong Ahafo region of Ghana. The variation of antenatal care, institutional delivery and postnatal care services utilization was high for Brong Ahafo region compared to other regions and even at the national level. The 2014 Ghana Demographic and Health Survey (GDHS) shows that regional variations in terms of the level of utilizing antenatal care (ANC), institutional delivery and postnatal care services are very high. The proportion of mothers who received ANC, delivered at health institutions, and made postnatal checkup in the first two days after birth was $90.3 \%, 78.3 \%$ and $80.1 \%$ respectively, for Brong Ahafo region while it was $97.0 \%, 73.0 \%, 78.0 \%$ percent, respectively, for the whole country (2014 GDHS). However, the reasons for the high level of utilization of these maternal health care services in the Brong Ahafo Region, with its own peculiar geographic, socio-economic, and cultural setting which might affect utilization of these services have not been investigated. The uses of these services in the Brong Ahafo region are relatively high compared to other regions in the country and the factors for this utilization in the region are not well examined. It is against this background that this study is being undertaken to determine the factors which influence antenatal care, institutional delivery and postnatal care services utilization among women in urban and rural communities in the Brong Ahafo Region of Ghana. Although previous studies [3] [9] [10] [11] have examined factors contributing to antenatal care, institutional delivery and postnatal care services utilization in Ghana, these studies have used national data limiting its applicability to some areas with specific characteristics. On the other hand, where specific areas or location have been used, these studies have mostly limited it to rural areas and also where the utilization is very low [12].

This study seeks to bridge the identified gaps by exploring the factors which influence the antenatal care, institutional delivery and postnatal care services utilization in urban and rural communities in the Brong Ahafo Region of Ghana, with its own peculiar geographic, socio-economic, and cultural setting, where the utilization of these services is also high. This study, therefore, seeks to model the geographic, socio-economic, and cultural factors which influence the antenatal care, institutional delivery and postnatal care services utilization in the Brong Ahafo Region. 


\subsection{Study Sample and Data Source}

The data are obtained from the 2014 Ghana Demographic and Health Survey (GDHS) [5]. The 2014 GDHS is part of the worldwide MEASURE DHS project which was funded by the U.S. Agency for International Development (USAID), the Global Fund, the United Nations Children's Fund (UNICEF), the United Nations Development Program (UNDP), the United Nations Population Fund (UNFPA), the International Labor Organization (ILO), the Danish International Development Agency (DANIDA), and the Government of Ghana, and was implemented by the Ghana Statistical Service (GSS) in collaboration with the National Public Health and Reference Laboratory (NPHRL) and the Ghana Health Service (GHS). A DHS is undertaken every 5 years and the 2014 survey is the 6th DHS in Ghana. The first DHS was carried out in 1988 and the 5th in 2008.

Data were collected from a representative sample of women and men in the reproductive age group of $15-49$ and 15 - 59 years respectively from all the ten regions of Ghana. The analysis was based on data from women who had at least one birth during the 5 years preceding the survey.

A national representative sample of 12,831 households was selected for the sample, of which 12,010 were occupied. Of the occupied households, 11,835 were successfully interviewed. From these households, a total of 9396 women in the reproductive age group of $15-49$ years and a total of 4388 men in the age group of 15 - 59 years were interviewed using a structured questionnaire. Out of this number, a total of 769 women in the reproductive age group of $15-49$ years representing 8.2 percent and 320 men in the reproductive age group of 15 - 59 years representing 8.3 percent in the Brong Ahafo Region took part in the study. For this study, women and men who had at least one birth in the last five years preceding the survey were included in the analysis. Because of the approximately equal sample sizes in each region, the sample was not self-weighting at the national level, and weighting factors were added to the data file so that the results would be proportional at the national level. As a result of that, a data file comprising of a total number of 2478 cases of women was used for the analysis.

\subsection{Description of the Outcome Variables}

An outcome variable is a variable whose value is being investigated/evaluated. The value of the outcome variable depends upon other variables known as independent/explanatory variables. We now describe the outcome/dependent/ response variables used in this study. In this study, we considered three outcome variables. These variables are antenatal care (ANC), institutional delivery (ID), and postnatal care (PNC), services utilization. In addition, the outcome of each of these variables is binary. For instance, the outcome of ANC is either a mother utilizes ANC service for at least 4 times or less than 4 times. The recommended number times for a mother to utilize ANC service is 4. For ANC, the outcome is coded 1 for at least 4 times and 0 for less than 4 times of ANC service utilization. The outcome of ID is whether a mother delivered at home or at a health facility. 
The ID variable takes a value of 1 if a mother delivered at a health facility and 0 if delivered at home. Also, the outcome of PNC is whether a mother utilizes PNC service within two months of delivery or not. It is recommended that mothers should seek for PNC service within two months of delivery. The PNC variable takes a value of 1 if a mother utilizes PNC service within two months of delivery and 0 if a mother does not utilize PNC service within two months of delivery. Table 1 shows the percentage distribution of the outcome variables. It can be observed that $9.20 \%$ utilized ANC services less than 4 times and $90.80 \%$ utilized ANC services for at least 4 times. Also, 22.50\% of the mothers delivered at home while $77.50 \%$ delivered at a health facility. For PNC service, $44.50 \%$ of the mothers do not utilize PNC service within 2 months of delivery while $55.50 \%$ utilized PNC service within 2 months of delivery.

Table 1. Background characteristics.

\begin{tabular}{|c|c|c|}
\hline Background Characteristics & $\mathrm{n}$ & $\%$ \\
\hline \multicolumn{3}{|l|}{ Maternal age } \\
\hline $12-19$ years & 1446 & 58.1 \\
\hline$\geq 20$ years & 1041 & 41.9 \\
\hline \multicolumn{3}{|l|}{ Maternal education } \\
\hline Uneducated & 998 & 40.1 \\
\hline Educated & 1489 & 59.9 \\
\hline \multicolumn{3}{|l|}{ Maternal marital status } \\
\hline Single & 364 & 14.6 \\
\hline Married & 2123 & 85.4 \\
\hline \multicolumn{3}{|l|}{ Maternal occupation } \\
\hline Unemployed & 185 & 7.4 \\
\hline Employed & 2302 & 92.6 \\
\hline \multicolumn{3}{|l|}{ Maternal wealth } \\
\hline Poor & 1552 & 62.4 \\
\hline Average & 533 & 21.4 \\
\hline Rich & 402 & 16.2 \\
\hline \multicolumn{3}{|l|}{ Maternal ethnic group } \\
\hline Akan & 1369 & 55.1 \\
\hline Non-Akan & 1118 & 44.9 \\
\hline \multicolumn{3}{|l|}{ Maternal religion } \\
\hline Christian & 1827 & 73.5 \\
\hline Non-Christian & 660 & 26.5 \\
\hline \multicolumn{3}{|l|}{ Maternal husband's education } \\
\hline Uneducated & 700 & 29.5 \\
\hline
\end{tabular}




\section{Continued}

\begin{tabular}{|c|c|c|}
\hline Educated & 1675 & 70.5 \\
\hline \multicolumn{3}{|c|}{ Maternal health insurance } \\
\hline No & 675 & 27.1 \\
\hline Yes & 1812 & 72.9 \\
\hline \multicolumn{3}{|l|}{ Parity } \\
\hline $1-4$ children & 1157 & 46.5 \\
\hline$\geq 5$ children & 1330 & 53.5 \\
\hline \multicolumn{3}{|c|}{ Geographical location } \\
\hline Urban & 918 & 36.9 \\
\hline Rural & 1569 & 63.1 \\
\hline \multicolumn{3}{|l|}{ Antenatal care } \\
\hline$<4$ & 45 & 9.2 \\
\hline$\geq 4$ & 442 & 90.8 \\
\hline \multicolumn{3}{|c|}{ Institutional delivery } \\
\hline Home & 147 & 22.5 \\
\hline Health facility & 506 & 77.5 \\
\hline \multicolumn{3}{|l|}{ Postnatal care } \\
\hline No & 218 & 44.5 \\
\hline Yes & 272 & 55.5 \\
\hline
\end{tabular}

\subsection{Description of the Explanatory or Independent Variables}

We have mentioned in the previous section that the outcome/dependent/ response variable depends on explanatory/independent/predictor variables. These variables determine or predict the value of the outcome variable. We now give a description of the explanatory variables. The explanatory variables are age (12 19 years or $>20$ years), education (uneducated or educated), marital status (single or married), occupation (unemployed or employed), wealth (poor, average, or rich), ethic group (Akan or non-Akan), religion (Christian or non-Christian), husband eduction (uneducated or educated), health insurance (No or Yes), parity ( $1-4$ or $\geq 5$ ), and residence (urban or rural). These variables were considered in this study based on experts advice and preliminary analysis.

\subsection{Percentage Distribution of the Study Variables}

Table 1 shows the percentage distribution of the women, who had delivered at least one child during the last five years preceding the survey by select background/baseline characteristics. Majority of the women who had given at least one child during the last five years preceding the survey were within 12 19 years. Approximately $40 \%$ of the mothers were uneducated and mothers who were singles constitutes $14.6 \%$ of the mothers. Most of the women in the 
study sample were reportedly employed and majority of the were from the poor homes. Also, most of the women's husbands were educated and majority of the women have health insurance. Majority of the women had at least 5 children and most of the women were from the rural communities. Most of the mothers utilized ANC service more than 4 times and delivered at a health facility.

\subsection{Statistical Methods}

In this study, we used two statistical methods. Firstly, we used the Chi-Square analysis [13] to assess the significance of the association between the outcome variable of interest (antenatal care, institutional delivery, or postnatal care) and explanatory variables. The explanatory variables discussed in the previous section were considered because they are more likely to have an influence on antenatal care, institutional delivery and postnatal care services utilization in the Brong Ahafo Region.

Secondly, we used the logistic regression model [14] [15] [16] to establish the relation between each of the outcome variables of interest (antenatal care, institutional delivery, or postnatal care) and the explanatory variables. For the logistic regression analysis, we fitted three multiple regression models for the ANC, ID and PNC and then adjust for the baseline characteristics or the explanatory variables.

The general form of a logistic regression model [14] [15] [16] can be written as

$$
\begin{aligned}
& \operatorname{logit}\left[\operatorname{Pr}\left(y_{i}=1 \mid \boldsymbol{X}, \boldsymbol{\beta}\right)\right] \\
& =\operatorname{logit}\left(p_{i}\right)=\log \left(\frac{p_{i}}{1-p_{i}}\right)=\beta_{0}+\beta_{1} X_{1}+\beta_{2} X_{2}+\cdots+\beta_{p} X_{p},
\end{aligned}
$$

where $x_{1}, \cdots, x_{p}$ are the explanatory variables, $\beta_{0}, \cdots, \beta_{p}$ are parameter estimates for the explanatory variables, $y_{i}$ is a binary outcome variable which equals one if an individual $i$ is exposed to an explanatory variable, $\boldsymbol{X}$ is a design matrix for the explanatory variables, $\beta$ is a vector of the parameter estimates. Also, $p_{i}$ is the probability of being affected by the explanatory variable and $\frac{p_{i}}{1-p_{i}}$ is the odds of the outcome variable among those who are exposed to the explanatory variable, relative to those who are not exposed to the same explanatory variable. So in effect, the $\boldsymbol{\beta}$ is the $\log$ odds ratio of the outcome variable for the exposure relative to non-exposure.

We consider a logistic regression model for socio-cultural and socio-economic variables under each of outcome variables, ANC, ID, and PNC. A logistic regression model for ANC can be written as

$$
\begin{aligned}
\operatorname{logit}[\operatorname{Pr}(\mathrm{ANC}=1)] \\
=\beta_{0}+\beta_{1} \text { age }+\beta_{2} \text { education }+\beta_{3} \text { maritalstatus }+\beta_{4} \text { employmen } \\
\quad+\beta_{5} \text { ethnicgroup }+\beta_{6} \text { religion }+\beta_{7} \text { husbandeducation } \\
+\beta_{8} \text { parity }+\beta_{9} \text { employmen }+\beta_{10} \text { wealth }+\beta_{2} \text { residence }
\end{aligned}
$$


Logistic regression models for ID and PNC would follow the same procedure in the model (1).

These statistical models/analyses were implemented using $\mathrm{R}$ version 3.5.2 [17] [18] [19] and STATA version 14.1 softwares [20] [21].

\section{Results}

In this section, we present the results of the analyses using the Chi-Square test of association and the logistic regression model for the binary response variables of interest. To identify factors associated with the utilization of maternal health-care services, namely, antenatal care (ANC), institutional delivery (ID), and postnatal care (PNC), we examined the bivariate differential of some selected socio-economic and socio-cultural variables. We will present the results of Chi-Square test of association first, followed by the results obtained using the logistic regression model.

\subsection{Results from the Chi-Square Analyses}

Table 2 presents the results of the Chi-Square test of association between the outcome variables and the background characteristics (explanatory variables).

Table 2. A Chi-Square test of association between outcome variables and baseline characteristics.

\begin{tabular}{|c|c|c|c|c|c|c|}
\hline \multirow[b]{2}{*}{ Variables $^{1}$} & \multicolumn{2}{|c|}{ Antenatal Care } & \multicolumn{2}{|c|}{ Institutional Delivery } & \multicolumn{2}{|c|}{ Postnatal Care } \\
\hline & $<4$ & $>4$ & Home & $\begin{array}{l}\text { Health } \\
\text { Facility }\end{array}$ & $>2$ months & $\leq 2$ months \\
\hline \multicolumn{7}{|l|}{ Maternal age } \\
\hline $12-19$ years & 10 & 90 & 25.5 & $74.5^{\star *}$ & 44.7 & 55.3 \\
\hline $20+$ years & 8.4 & 91.6 & 19.2 & 80.8 & 44.3 & 55.7 \\
\hline \multicolumn{7}{|c|}{ Maternal education } \\
\hline Uneducated & 14.0 & $86.0^{* *}$ & 40.1 & $59.9^{* *}$ & 52.8 & $47.2^{\star *}$ \\
\hline Educated & 7.3 & 92.7 & 14.6 & 85.4 & 41.0 & 59.0 \\
\hline \multicolumn{7}{|c|}{ Maternal marital status } \\
\hline Single & 12.8 & 87.2 & 13 & $87^{\star *}$ & 36.8 & 63.2 \\
\hline Married & 8.5 & 91.5 & 24.2 & 75.8 & 46.2 & 53.8 \\
\hline \multicolumn{7}{|c|}{ Maternal occupation } \\
\hline Unemployed & 13.3 & 86.7 & 12.5 & $87.5^{\star *}$ & 42.1 & 57.9 \\
\hline Employed & 8.5 & 91.5 & 24.2 & 75.8 & 44.9 & 55.1 \\
\hline \multicolumn{7}{|l|}{ Maternal wealth } \\
\hline Poor & 11.8 & $88.2^{\star *}$ & 32.9 & $67.1^{* *}$ & 45.2 & 54.8 \\
\hline Average & 7.4 & 92.6 & 11.6 & 88.4 & 44.4 & 55.6 \\
\hline
\end{tabular}

${ }^{1 * *}$ notes explanatory variables that are potential determinants of ANC, ID, or PNC. 


\section{Continued}

\begin{tabular}{|c|c|c|c|c|c|c|}
\hline Rich & 3.3 & 96.7 & 1.7 & 98.3 & 42.4 & 57.6 \\
\hline \multicolumn{7}{|c|}{ Maternal ethnic group } \\
\hline Akan & 8.7 & 91.3 & 17.7 & $82.3^{* * *}$ & 45.7 & 54.3 \\
\hline Non-Akan & 10.0 & 90.0 & 28.9 & 71.1 & 42.9 & 57.1 \\
\hline \multicolumn{7}{|l|}{ Maternal religion } \\
\hline Christian & 9.1 & 90.9 & 21.2 & 78.8 & 44.6 & 55.4 \\
\hline Non-Christian & 9.5 & 90.5 & 26.1 & 73.9 & 44.1 & 55.9 \\
\hline \multicolumn{7}{|c|}{$\begin{array}{c}\text { Maternal } \\
\text { husband's education }\end{array}$} \\
\hline Uneducated & 14.7 & $85.3^{* *}$ & 34.8 & $65.2^{* *}$ & 44.7 & 55.3 \\
\hline Educated & 7 & 93 & 20.1 & 79.9 & 45.8 & 54.2 \\
\hline \multicolumn{7}{|l|}{$\begin{array}{c}\text { Maternal } \\
\text { health insurance }\end{array}$} \\
\hline No & 11.6 & 88.4 & 29.2 & $70.8^{* *}$ & 48.4 & 51.6 \\
\hline Yes & 8.5 & 91.5 & 20.3 & 79.7 & 43.2 & 56.8 \\
\hline \multicolumn{7}{|l|}{ Parity } \\
\hline 1 - 4 children & 6.5 & $93.5^{\star *}$ & 17.0 & $83.0^{* *}$ & 43.4 & 56.6 \\
\hline$>5$ children & 16.3 & 83.7 & 35.2 & 64.8 & 47.4 & 52.6 \\
\hline \multicolumn{7}{|c|}{ Geographical location } \\
\hline Urban & 5.5 & $94.5^{\star *}$ & 9.3 & $90.7^{\star *}$ & 38.8 & $61.2^{* \star}$ \\
\hline Rural & 11.9 & 88.1 & 31.9 & 68.1 & 48.4 & 51.6 \\
\hline
\end{tabular}

\subsubsection{ANC versus Explanatory Variables}

The results showed that there is no significant association between maternal age, marital status, employment status, ethnic group, religion, or health insurance and ANC services utilization at $5 \%$ level of significance. There is a significant (p-value $=0.0001<0.05)$ association between maternal education and the number of ANC services utilization. The results revealed there is significant ( $\mathrm{p}$-value $=0.0234<0.05)$ association between the wealth status of a mother and ANC services utilization and there is a significant association ( $p$-value $=0.0045<0.05$ ) maternal husband's educational status and ANC services utilization. The study also found that parity was significantly ( $\mathrm{p}$-value $=0.0034<0.05$ ) associated with ANC services utilization and that a mother's geographical location is significantly (p-value $=0.0012<0.05)$ associated with ANC services utilization.

\subsubsection{Institutional Delivery versus Explanatory Variables}

The results in Table 2 showed that there was no significant association between religious status and institutional delivery (ID). The results also revealed that ID was significantly associated with maternal age ( $\mathrm{p}$-value $=0.0341<0.05)$, educational status ( $\mathrm{p}$-value $=0.0042<0.05)$, marital status $(\mathrm{p}$-value $=0.0143<0.05)$, employment status $(\mathrm{p}$-value $=0.0031<0.05)$, wealth status $(\mathrm{p}$-value $=0.0234<$ 
$0.05)$, ethnic group ( $\mathrm{p}$-value $=0.0153<0.05$ ), husband's educational status ( -value $=0.025<0.05)$, parity ( -value $=0.0034<0.05)$, or geographical location $(\mathrm{p}$-value $=0.0034<0.05)$.

\subsubsection{Postnatal Care Services versus Explanatory Variables}

The results in the column 3 of Table 2 showed that there was no significant association between PNC service utilization and maternal age, marital status, employment status, wealth, ethnic group, religious status, husband's educational status, health insurance, or parity. On the other hand, the results showed a significant association between PNC service utilization and maternal educational status $(\mathrm{p}$-value $=0.0044<0.05)$ and geographical location $(\mathrm{p}$-value $=0.0034<0.05)$.

\subsection{Results from the Logistic Regression Analysis}

In this section, we assessed the effect of socio-economic and socio-cultural explanatory variables on the outcome variables, antenatal care (ANC), institutional delivery (ID), and postnatal care (PNC) services utilization. To determine the effects of the socio-economic and socio-cultural factors on the outcome variables, we regress each of the outcome variables on the socio-economic and socio-cultural factors. The adjusted odds ratios are shown in Table 3 columns 1, 2, and 3 for ANC, ID, and PNC outcome variables respectively. The unadjusted odds ratios are presented in Table 4.

\subsubsection{Effects of Socio-Cultural and Socio-Economic Factors on ANC Service Utilization}

The results showed that all the socio-cultural explanatory variables are not significant predictors of ANC service utilization, except parity. That is, women with at least 5 children were less likely to utilize ANC service relative to women who had experienced childbirth for less than five times (OR $=0.374,95 \% \mathrm{CI}$ : 0.173 - 0.796). All the socio-economic variables (wealth status, health insurance status, and geographical location of a mother) are not significant predictors of ANC service utilization. This means that, after we have adjusted for the explanatory variables, only parity is significant predictor of ANC service utilization.

\subsubsection{Effects of Socio-Cultural and Socio-Economic Factors on ID Service Utilization}

For the socio-cultural explanatory variables, our statistical analyses showed that maternal age, marital status, employment status, ethnic group, religious group, and husband's educational status are not significant predictors of institutional delivery (ID) service utilization. On the other hand, we found that maternal educational status and parity are significant predictors of ID service utilization. Thus, the odds of delivering in a health facility among women who had formal education $(\mathrm{OR}=3.171,95 \% \mathrm{CI}: 1.929-5.257)$ was 3.2 times higher than uneducated women. Also, women had five or more births were less likely to deliver in a health facility relative to women who had experienced childbirth for less than five times (OR $=0.609,95 \% \mathrm{CI}$ : $0.395-0.940)$. 
Table 3. Adjusted odds ratio and $95 \%$ confidence interval (95\% CI): logistic regression model.

\begin{tabular}{|c|c|c|c|c|c|c|}
\hline & \multicolumn{2}{|c|}{ Antenatal Care } & \multicolumn{2}{|c|}{ Institutional Delivery } & \multicolumn{2}{|c|}{ Postnatal Care } \\
\hline Covariates & Odds Ratio & $95 \% \mathrm{CI}$ & Odds Ratio & $95 \% \mathrm{CI}$ & Odds Ratio & $95 \% \mathrm{CI}$ \\
\hline \multicolumn{7}{|c|}{ Socio-cultural determinants: } \\
\hline \multicolumn{7}{|l|}{ Maternal age } \\
\hline $12-19$ years & 1 (reference) & & 1 (reference) & & 1 (reference) & \\
\hline $20+$ years & 0.852 & $(0.423,1.718)$ & 1.286 & $(0.855,1.941)$ & 1.052 & $(0.714,1.549)$ \\
\hline
\end{tabular}

\section{Maternal education}

Uneducated

Educated

Maternal marital status

Single
Married
Maternal
occupation
Unemployed
Employed

\section{Maternal ethnic group}

$$
\text { Akan }
$$

Non-Akan

\section{Maternal religion}

Christian

Non-Christian

Maternal

husband's education

\section{Uneducated \\ Educated}

\section{Parity}

$$
1 \text { - } 4 \text { children }
$$

$>5$ children

Socio-economic determinants:

Maternal wealth

$\begin{array}{cc}\text { Poor } & 1 \text { (reference) } \\ \text { Average } & 1.372 \\ \text { Rich } & 2.776\end{array}$

\section{Maternal}

health insurance

$\begin{array}{cc}\text { No } & 1 \text { (reference) } \\ \text { Yes } & 1.197\end{array}$

$$
1.197
$$

$(0.592,2.319)$

$(0.744,4.187)$

$\begin{array}{ll}1 \text { (reference) } & \\ 1.674 & (0.713,3.925) \\ & \\ 1 \text { (reference) } & \\ 0.374 & (0.173,0.796)\end{array}$

1 (reference)

$$
1.849
$$

$$
3.171
$$

$(1.929,5.257)$
1 (reference)

.003

(reference)

$(0.498,2.318)$

1 (reference)

0.823

$(0.526,1.295)$

1 (reference)

1.214

$(0.762,1.958)$

1 (reference)

1.033

$(0.646,1.656)$
$(0.405,1.380)$

reference)

1 (reference)

$1.373 \quad(0.892,2.126)$

1 (reference)

1 (reference)

0.944

$(0.561,1.576)$

0.753

$(0.436,1.287)$

1 (reference)

1 (reference)

0.609

$(0.395,0.940)$

1.032

$(0.659,1.621)$

\section{Geographical location}

\begin{tabular}{ccccccc} 
Urban & 1 (reference) & \multicolumn{3}{c}{1 (reference) } & \multicolumn{3}{c}{1 (reference) } \\
Rural & 0.653 & $(0.268,1.474)$ & 0.539 & $(0.312,0.908)$ & 0.569 & $(0.350,0.913)$ \\
\hline
\end{tabular}


Table 4. Unadjusted odds ratio and 95\% confidence interval (95\% CI): logistic regression model.

\begin{tabular}{|c|c|c|c|c|c|c|}
\hline \multirow[b]{2}{*}{ Covariates } & \multicolumn{2}{|c|}{ Antenatal Care } & \multicolumn{2}{|c|}{ Institutional Delivery } & \multicolumn{2}{|c|}{ Postnatal Care } \\
\hline & Odds Ratio & $95 \% \mathrm{CI}$ & Odds Ratio & $95 \%$ CI & Odds Ratio & $95 \% \mathrm{CI}$ \\
\hline \multicolumn{7}{|c|}{ Socio-cultural determinants: } \\
\hline \multicolumn{7}{|l|}{ Maternal age } \\
\hline $12-19$ years & 1 (reference) & & 1 (reference) & & 1 (reference) & \\
\hline $20+$ years & 0.187 & $(-0.429,0.819)$ & 0.368 & $(-0.003,0.745)$ & 0.0145 & $(-0.343,0.372)$ \\
\hline \multicolumn{7}{|c|}{ Maternal education } \\
\hline Uneducated & 1 (reference) & & 1 (reference) & & 1 (reference) & \\
\hline Educated & 0.7299 & $(0.097,1.352)$ & 1.362 & $(0.980,1.749)$ & 0.474 & $(0.083,0.866)$ \\
\hline \multicolumn{7}{|c|}{ Maternal marital status } \\
\hline Single & 1 (reference) & & 1 (re1ference) & & 1 (reference) & \\
\hline Married & 0.459 & $(-0.305,1.155)$ & -0.761 & $(-1.418,-0.180)$ & -0.387 & $(-0.874,0.085)$ \\
\hline \multicolumn{7}{|c|}{ Maternal occupation } \\
\hline Unemployed & 1 (reference) & & 1 (reference) & & 1 (reference) & \\
\hline Employed & 0.505 & $(-0.293,1.223)$ & -0.806 & $(-1.488,-0.207)$ & -0.115 & $(-0.616,0.377)$ \\
\hline \multicolumn{7}{|l|}{$\begin{array}{l}\text { Maternal } \\
\text { ethnic group }\end{array}$} \\
\hline Akan & 1 (reference) & & 1 (reference) & & 1 (reference) & \\
\hline Non-Akan & -0.149 & $(-0.764,0.473)$ & -0.638 & $(-1.011,-0.269)$ & 0.112 & $(-0.248,0.473)$ \\
\hline \multicolumn{7}{|c|}{ Maternal religion } \\
\hline Christian & 1 (reference) & & 1 (reference) & & 1 (reference) & \\
\hline Non-Christian & -0.045 & $(-0.714,0.686)$ & -0.276 & $(-0.673,0.132)$ & 0.022 & $(-0.384,0.431)$ \\
\hline \multicolumn{7}{|c|}{$\begin{array}{l}\text { Maternal husband's } \\
\text { education }\end{array}$} \\
\hline Uneducated & 1 (reference) & & 1 (reference) & & 1 (reference) & \\
\hline Educated & 0.827 & $(0.117,1.512)$ & 0.751 & $(0.331,1.165)$ & -0.044 & $(-0.491,0.399)$ \\
\hline \multicolumn{7}{|l|}{ Parity } \\
\hline 1 - 4 children & 1 (reference) & & 1 (reference) & & 1 (reference) & \\
\hline$>5$ children & -1.024 & $(-1.649,-0.398)$ & -0.977 & $(-1.358,-0.596)$ & -0.163 & $(-0.560,0.236)$ \\
\hline \multicolumn{7}{|c|}{ Socio-economic determinants: } \\
\hline \multicolumn{7}{|l|}{ Maternal wealth } \\
\hline Poor & 1 (reference) & & 1 (reference) & & 1 (reference) & \\
\hline Average & 0.519 & $(-0.239,1.390)$ & 1.322 & $(0.798,1.901)$ & 0.029 & $(-0.414,0.476)$ \\
\hline Rich & 1.383 & $(0.328,2.824)$ & 3.339 & $(2.171,5.150)$ & 0.113 & $(-0.359,0.591)$ \\
\hline \multicolumn{7}{|l|}{$\begin{array}{l}\text { Maternal health } \\
\text { insurance }\end{array}$} \\
\hline No & 1 (reference) & & 1 (reference) & & 1 (reference) & \\
\hline Yes & 0.346 & $(-0.348,0.997)$ & 0.480 & $(0.071,0.881)$ & 0.208 & $(-0.204,0.619)$ \\
\hline \multicolumn{7}{|l|}{$\begin{array}{c}\text { Geographical } \\
\text { location }\end{array}$} \\
\hline Urban & 1 (reference) & & 1 (reference) & & 1 (reference) & \\
\hline Rural & -0.846 & $(-1.595,-0.171)$ & -1.522 & $(-2.005,1.073)$ & -0.393 & $(-0.761,-0.029)$ \\
\hline
\end{tabular}


For the socio-economic variables, the statistical analyses showed that maternal health insurance status is not a significant predictor of ID service utilization. However, maternal wealth and geographical location are significant predictors of ID service utilization. Thus, women from the average wealth quintiles were 2.8 times more likely (OR $=2.821,95 \% \mathrm{CI}: 1.595$ - 5.233) to deliver in a health facility compared to those from the poor wealth quintile. In addition, women from the rich wealth quintile are 16.9 times more likely (OR $=16.877,95 \%$ CI: 4.816 107.124) to deliver in a health facility compared to those from the poor wealth quintile. Mothers who lived in rural communities are less likely $(\mathrm{OR}=0.539$, 95\% CI: $0.312-0.908$ ) to deliver in a health facility relative to those living in urban communities.

\subsubsection{Effects of Socio-Cultural and Socio-Economic Factors on PNC Services Utilization}

For the socio-cultural explanatory variables, our statistical analyses showed that maternal age, marital status, employment status, ethnic group, religious status, husband's educational status, and parity are not significant predictors of postnatal care (PNC) service utilization. On the other hand, we found that maternal educational status is a significant predictor of PNC service utilization. Thus, women who had formal education are 1.8 times likely ( $\mathrm{OR}=1.849,95 \%$ CI: 1.109 - 3.119) to utilize PNC service within two months of delivery relative to the uneducated women. For the socio-economic variables, the statistical analyses showed that maternal wealth status and health insurance status are not significant predictors of PNC service utilization. Only maternal geographical location is significant predictors of PNC service utilization. Thus, mothers who lived in rural communities are less likely $(\mathrm{OR}=0.569,95 \% \mathrm{CI}: 0.350-0.913)$ to deliver at a health facility relative to those living in urban communities.

\section{Discussion}

The purpose of this study was to determine the factors which influence the antenatal care (ANC), institutional delivery (ID), and postnatal care (PNC) services utilization in the Brong Ahafo Region of Ghana. We used the 2014 Ghana DHS data set. This study has investigated significance of factors affecting the use of maternity care services, with the aim of improving the information available to decision-makers who are responsible for planning and administering maternal care programs.

We considered various risk factors such as maternal age, educational status, employment status, marital status, religious status, ethnic group, parity, wealth, geographical location, health insurance, and husband's educational status, and then investigate their effect of ANC, ID, and PNC services utilization. This study identified factors that are significant predictors of the outcome variables, ANC, ID, and PNC. These factors are geographical location (rural/urban), mother and husbands educational status, household wealth quintile, and parity. The study 
results showed that utilization of maternal health-care services is highly and significantly associated with maternal education. This is because education improves communication between mothers and husbands and other family members on pregnancy and childbirth health-related issues. By doing so, mothers are able to take part in decisions making regarding their health as well as the child's health. As a result, there is better communication between these parties, and such women are more likely to seek quality health-care services relative to the uneducated woman. Parity was found to have a significant effect antenatal care service utilization such that there is a reduced chance of antenatal care service utilization among women with five or more births relative to women who had experienced childbirth for less than five times.

For institutional delivery service utilization, maternal educational status, husband's educational status, household wealth status, ethnic group, and parity are significant predictors of institutional delivery service utilization. This is an indication that 1) with increasing level of education there is a corresponding increase in the chance to deliver at a health facility, 2) women from the rich homes are more likely to deliver in a health facility relative to those from average and poor homes, 3) women with five or more births are less likely to deliver in a health facility relative to women who had experienced childbirth for less than five times, and 4) living in the rural communities in the Brong Ahafo Region makes it less likely for the women to deliver at a health facility relative to living in the urban communities.

For postnatal care (PNC) service utilization, educationd women are more likely to utilize PNC service within two months of delivery relative to the uneducated mothers and women living in the rural communities are likely to use PNC service within 2 months of delivery relative to their counterparts in the urban communities. That is women living in urban cities are more exposed to health facilities responsible for providing postnatal care services and are, therefore, always likely to utilize postnatal care services compared with those in rural communities.

\section{Conclusions}

Providing education for women can significantly improve their ability to utilize postnatal care services. Mothers with more experience of childbirths are not willing to seek maternal health care services. This again emphasizes the need to provide education for mothers on the importance/benefits of seeking maternal health care services. Mothers from rich homes and urban communities prefer to deliver at a health facility. This implies that there is a need to encourage measures that provide means (eg. transportation or income) to assist poor or average wealth mothers to seek maternal care services. Also, measures to improve maternal care services utilization should focus on building health facilities in rural communities so that mothers can have easy access to maternal care services.

Findings from this study suggest that maternal health care policies and pro- 
grams should include promoting easy and affordable access of women to higher educational opportunities. Government and policy-makers should promote the provision of affordable or free maternal care health services to mothers since there is significantly high variability in the use of maternal health care services between wealthier and poorer women. For instance, government through the social poverty reduction schemes (such as the LEAP) should support the women in the region especially the rural communities in the region. That is, government policies and programs should focus on poor women in households and specific subgroups with communities to enhance mothers access to maternal health-care services utilization. The rural areas of the region should be given enough health-care facilities to be able to address the low coverage of maternal health-care utilization among the rural women.

It was revealed that women with higher parity were less likely to use maternity care services than those with lower parity. This means that the likelihood of utilization of maternal health-care services with older women in the region will be gradually declining with higher birth order. This could lead to adverse health outcomes for both the mother and the child. It is, therefore, recommended that local health workers such as the community health nurses should make visits to households for appropriate counseling and education regarding the utilization of maternal health-care services. The media, radio, and television should also be used for such a campaign. For further research, it is recommended that a cross-study be done to examine the determinants of the maternal health care utilization in low coverage region and high coverage region, in order to find out the factors accounting for the gap.

\section{Authors' Contributions}

AK performed the literature review, statistical analyses, interpretation of findings, and wrote the article. DO and BM contributed in interpretation of results and reviewing the manuscript. The final version has been approved by the authors.

\section{Acknowledegments}

The author would like to acknowledge Fauzia Issah for proof-reading the paper.

\section{Availability of Data and Materials}

The data used are from Ghana Demographic and Health Survey and can be found on https://www.dhsprogram.com/data/.

\section{Funding}

The study receives no funding.

\section{Ethics Approval (and Consent to Participate)}

Ethics approval and consent to participate statements can be found on https://www.dhsprogram.com/data/. Procedures and questionnaires for stan- 
dard DHS surveys have been reviewed and approved by the ICF International Institutional Review Board (IRB). Additionally, country-specific DHS survey protocols are reviewed by the ICF IRB and typically by an IRB in the host country. The ICF International IRB ensures that the survey complies with the U.S. Department of Health and Human Services regulations for the protection of human subjects ( 45 CFR 46), while the host country IRB ensures that the survey complies with laws and norms of the nation. Before each interview or biomarker test is conducted, an informed consent statement is read to the respondent, who may accept or decline to participate. A parent or guardian must provide consent prior to participation by a child or adolescent. DHS informed consent statements provide details regarding: the purpose of the interview/test, the expected duration of the interview, interview/test procedures, potential risks to the respondent. Potential benefits to the respondent, contact information for a person who can provide the respondent with more information about the interview/test. Most importantly, the informed consent statement emphasizes that participation is voluntary; that the respondent may refuse to answer any question, decline any biomarker test, or terminate participation at any time; and that the respondent's identity and information will be kept strictly confidential.

\section{Consent to Publish}

Not applicable.

\section{Conflicts of Interest}

The authors declare no conflicts of interest regarding the publication of this paper.

\section{References}

[1] WHO (2016) World Health Statistics 2016. Geneva.

[2] WHO (2014) Annual Technical Report 2013: Department of Reproductive Health and Research, Including UNDP UNFPA WHO World Bank, Special Programme of Research Training in Human Reproduction (HRP).

[3] Addai, I. (2000) Determinants of Use of Maternal-Child Health Services in Rural Ghana. Journal of Biosocial Science, 32, 1-15.

[4] WHO (2016) Maternal Mortality Fact Sheets. http://www.who.org

[5] GHS GSS (2014) Ghana Demographic and Health Survey Report. ICF International, Fairfax.

[6] World Bank (2015) Over 99 Percent of Maternal Deaths Occur in Developing Countries.

http://data.worldbank.org/news/over-99-percent-of-maternaldeaths-occur-in-devel oping-countries

[7] Witter, S., Arhinful, D.K., Kusi, A. and Zakariah-Akoto, S. (2007) The Experience of Ghana in Implementing a User Fee Exemption Policy to Provide Free Delivery Care. Reproductive Health Matters, 15, 61-71. https://doi.org/10.1016/S0968-8080(07)30325-X

[8] Ghana Statistical Service (2008) Ghana Demographic and Health Survey. Fact Sheet. 
[9] Arthur, E. (2012) Wealth and Antenatal Care Use: Implications for Maternal Health Care Utilisation in Ghana. Health Economics Review, 2, 14. https://doi.org/10.1186/2191-1991-2-14

[10] Browne, J.L., Kayode, G.A., Arhinful, D., Fidder, S.A.J., Grobbee, D.E. and Klipstein-Grobusch, K. (2016) Health Insurance Determines Antenatal, Delivery and Postnatal Care Utilisation: Evidence from the Ghana Demographic and Health Surveillance Data. BMJ Open, 6, e008175. https://doi.org/10.1136/bmjopen-2015-008175

[11] Dixon, J., Tenkorang, E.Y., Luginaah, I.N., Kuuire, V.Z. and Boateng, G.O. (2014) National Health Insurance Scheme Enrolment and Antenatal Care among Women in Ghana: Is There Any Relationship? Tropical Medicine \& International Health, 19, 98-106. https://doi.org/10.1111/tmi.12223

[12] Akum, F.A. (2013) A Qualitative Study on Factors Contributing to Low Institutional Child Delivery Rates in Northern Ghana: The Case of Bawku Municipality. Journal of Community Medicine and Health Education, 3, 236. https://doi.org/10.4172/2161-0711.1000236

[13] McHugh, M.L. (2013) The Chi-Square Test of Independence. Biochemia Medica, 23, 143-149. https://doi.org/10.11613/BM.2013.018

[14] Hosmer Jr., D.W., Lemeshow, S. and Sturdivant, R.X. (2013) Applied Logistic Regression, Volume 398. John Wiley \& Sons, Hoboken. https://doi.org/10.1002/9781118548387

[15] Menard, S. (2002) Applied Logistic Regression Analysis, Volume 106. Sage, Thousand Oaks. https://doi.org/10.4135/9781412983433

[16] Allison, P.D. (2012) Logistic Regression Using SAS: Theory and Application. SAS Institute, Cary.

[17] R Core Team, et al. (2016) R: A Language and Environment for Statistical Computing.

[18] R Core Team (2014) R: A Language and Environment for Statistical Computing. R Foundation for Statistical Computing, Vienna.

[19] Healy, K. (2005) Book Review: An R and S-Plus Companion to Applied Regression. Sociological Methods \& Research, 34, 137-140. https://doi.org/10.1177/0049124105277200

[20] LP StataCorp, et al. (2007) STATA: Data Analysis and Statistical Software. Special Edition Release, 10, 733.

[21] Statt Stata (2013) Release 13. Statistical Software. StataCorp LP, College Station. 